\title{
Pulgarcita y pulgarcito en el siglo XXI95
}

Antes de enseñar lo que sea, a quien sea, por lo menos es necesario conocerlo.

¿Quién se presenta hoy en día en la escuela, en el colegio, en la universidad?

\section{$-I-$}

Este nuevo escolar, esta joven estudiante, nunca han visto un becerro, una vaca, un cerdo mucho menos un nido. En 1900, la mayoría de los humanos sobre el planeta, se ocupaban de la agricultura y la ganaderia; en el 2010 Francia, como otros países semejantes al nuestro, sólo cuenta con un $1 \%$ de campesinos. Sin duda hay que ver alli una de las más inmensas rupturas de la historia desde el neolítico. En otro momento, referida a las prácticas geórgicas, la cultura cambia.

Aquel o aquella que les presento ya no vive en compañía de los vivos, ya no vive en la misma tierra, no tiene pues la misma relación con el mundo. Él o ella solo ven la naturaleza arcadiana de las vacaciones, del tiempo libre o del turismo.

Él habita la ciudad. Sus predecesores inmediatos, mucho más de la mitad, trabajaban el campo. No obstante, él se ha vuelto sensible a las cuestiones del medio. Prudente, él contaminará menos que los demás, adultos, inconscientes y narcisos.

Ya no posee el mismo mundo vital, ni el mismo mundo en número, la demografía de repente ha dado un salto hacia los siete mil millones de humanos.

Su esperanza de vida es, al menos, de ochenta años. El dia de su matrimonio, sus bisabuelos se habrían jurado fidelidad por apenas un decenio. Que él y ella consideren vivir en compañía, ¿jurarán lo mismo por 65 años? Sus padres recibieron la herencia hacia los treinta años, ellos deberán llegar a la vejez para recibirla.

\footnotetext{
${ }^{95}[\mathrm{NdE}]$ Conferencia pronunciada en la Sesión Solemne del Instituc de France dedicada a "Los nuevos desafios de la educación" el dia martes 1 de marzo del año 2011. Versión española del profesor Miguel Ångel Mahecha B.

${ }^{9}$ Michel Serres, nacido en Agen (Lot-et-Garonne) el primero de septiembre de 1930. Es un filósofo, historiador de las ciencias y hombre de letras francés. Sus obras más conocidas son Le système de Leibniz et ses modèles mathématiques, Presses universitaires de France ; Hermès I, la communication, Éditions de Minuit, Paris, Hermès II, l'interférence, Éditions de Minuit, Paris Hermès III, la traduction, Éditions de Minuit, Paris y su más reciente publicación (2010) Biogée, Ėditions-dialogues.fr/Le Pommier, Brest/Paris.
} 
Ya no tienen la misma vida, no viven las mismas edades, no conocen el mismo matrimonio ni la misma transmisión de bienes.

Desde hace 60 años, intervalo único en nuestra historia, él y ella no han conocido la guerra, ni a sus dirigentes ni a sus profesores. Al beneficiarse del progreso de la medicina y de la farmacia con los analgésicos y anestésicos, han sufrido, estadisticamente hablando menos que sus predecesores. ¿Acaso han padecido hambre?

Ahora bien, ya sea laica o religiosa, toda moral se resumía en ejercicios destinados a soportar un dolor inevitable y cotidiano: enfermedades, hambrunas, crueldad en el mundo.

Ellos ya no tienen el mismo cuerpo ni la misma conducta; ningún adulto ha sabido ni ha podido inspirarles una moral adaptada.

Mientras que sus padres fueron concebidos a ciegas, su nacimiento fue programado. Como para el primer niño, la edad promedio de la madre ha pasado de diez a quince años, los profesores ya no encuentran padres de niños que pertenezcan a la misma generación.

Ellos ya no tienen los mismos padres; al cambiar la sexualidad, su genitalidad se transformará.

Mientras que sus predecesores se reúnen en las clases o en los anfiteatros homogéneos culturalmente, ellos estudian en el seno de un colectivo en donde se entretejen, entre otras cosas, religiones, lenguas, procedencias y costumbres. Para ellos y sus profesores, el multiculturalismo es regla desde hace ya varios decenios. ¿Durante cuánto tiempo podrían ellos cantar el innoble " sang impur " de algún extranjero...?
Ellos no tienen el mismo mundo universal, ya no tienen el mismo mundo humano. Alrededor de ellos las hijas e hijos de inmigrantes, procedentes de países menos ricos, han vivido experiencias vitales inversas.

Resumen temporal. ¿Qué literatura, qué historia, comprenderán ellos, felices sin haber experimentado la rusticidad, las bestias domésticas y la cosecha de verano, conflictos, heridos, muertos y hambrientos, cementerios, patria, bandera ensangrentada, monumentos a los muertos, sin haber experimentado con sufrimiento la urgencia vital de una moral?

-II-

\section{Lo que es para el cuerpo, lo es para el conocimiento.}

Sus ancestros cultivados tenían, detrás de sí, un horizonte temporal de algunos miles de años decorados por la prehistoria, las tabletas cuneiformes, la Biblia judía, la Antigüedad grecolatina. Milenario a pesar de todo, su horizonte temporal se remonta a la barrera de Planck, pasa por el crecimiento del planeta, la evolución de las especies, una paleoantropología milenaria.

Al no habitar ya el mismo tiempo, ellos entraron en otra historia, completamente diferente.

Ellos son formateados por los medios, difundidos por adultos que han destruido meticulosamente su facultad de atención reduciendo la duración de las imágenes a siete segundos y el tiempo de respuestas a preguntas, en quince segundos, cifras oficiales; cuya palabra más repetida es "muerte" y la imagen más recurrente es la de los cadáveres. Desde los doce años de edad, estos adultos los obligan a ver más de veinte mil muertes.

Ellos son formateados por la publicidad, ¿cómo 
puede enseñárseles que la palabra relais en francés se escribe -ais mientras que en todas las estaciones de tren se ve escrito -ay?

¿Cómo puede enseñárseles el sistema métrico, cuando de la manera más descabellada, la SNCF les vende s'miles?

Nosotros los adultos hemos doblado nuestra sociedad del espectáculo en una sociedad pedagógica cuya concurrencia aplastante, vanidosamente inculta, eclipsa a la escuela y a la universidad. Para el tiempo de escucha y de visión, la seducción y la importancia, los medios se han apropiado desde hace tiempo de la función de enseñanza.

Los profesores han sido cada vez los menos escuchados entre estos maestros. Criticados, despreciados, vilipendiados, e incluso mal remunerados.

Los jóvenes viven en lo virtual. Las ciencias cognitivas muestran que el uso de la red, la lectura y la escritura de mensajes con el pulgar, consulta de Wikipedia o de Facebook, no excitan las mismas neuronas ni las mismas zonas corticales que el uso del libro, de la pizarra o del cuaderno. Ellos pueden manipular varios datos a la vez. Ellos no conocen ni integran ni sintetizan como sus predecesores.

Ellos ya no tienen la misma cabeza. A través del teléfono celular, acceden a cualquier persona; a través del GPS, a todos los lugares, por medio de la red a todo el saber; ellos aceleran un espacio topológico de vecindarios, mientras que nosotros vivimos en un espacio métrico, relacionado con las distancias.

Ellos ya no viven en el mismo espacio.

Sin que nos diéramos cuenta de ello, un nuevo humano nació, durante un intervalo breve, el que nos separa de la Segunda Guerra Mundial.

Él o ella ya no tienen el mismo cuerpo, ni la misma esperanza de vida, ya no viven en el mismo espacio, no comunican de la misma manera, no perciben el mismo mundo exterior, ya no viven en la misma naturaleza; nacido bajo anestesia y con fecha programada, no le teme a la muerte, incluso en cuidados intensivos. Ya no tiene la misma cabeza de sus padres, él o ella conocen de otra manera.

Él o ella escriben de otra forma. Basta observarlo, con admiración, enviar más rápidamente de lo que podría hacerlo con mis dedos tiesos, enviar vuelvo a decirlo SMS con los dos pulgares, y por eso los bauticé con la mayor ternura que pueda mostrar un abuelo, Pulgarcita y Pulgarcito. He ahí su nombre, mucho más bello que la antigua denominación pseudo-científica de mecanógrafo.

Ellos ya no hablan la misma lengua. Desde Richelieu, la Academia Francesa publica, más o menos cada cuarenta años, como referencia, nuestro diccionario. En los siglos anteriores, la diferencia entre dos publicaciones se establecía alrededor de cuatro a cinco mil palabras, cifras más o menos constantes; entre la edición precedente y la próxima, la diferencia estará alrededor de los treinta mil.

A ese ritmo lingüístico, podemos adivinar que dentro de pocas generaciones, nuestros herederos podrán estar tan separados de nosotros así como lo estamos nosotros del antiguo francés de Chrétien de Troyes o de Joinville. Este gradiente nos da una indicación cuasi fotográfica de los cambios mayores que describo.

Esta inmensa diferencia, que afecta a todas las lenguas, se debe, en parte, a la ruptura entre los 
saberes de los años cincuenta y los actuales. Pulgarcita y su hermano no se afanarán en los mismos trabajos.

La lengua cambió, el trabajo mutó.

\section{III $\mathrm{El}$ individuo}

Mejor aún, helos aqui convertidos en individuos. Inventado por san Pablo, a comienzos de nuestra era, el individuo acaba de nacer solamente en estos días. ¿Acaso nos hemos dado cuenta hasta qué punto vivíamos de accesorios desde hacía tanto tiempo hasta ahora? Franceses, católicos o judios, Gascones o Picardos, ricos o pobres, mujeres o machos...pertenecíamos a regiones, religiones, culturas, rurales o urbanas, grupos singulares, comunas locales, un sexo, la patria. A causa de los viajes, las imágenes, la red, las guerras abominables, estos colectivos han casi explotado. Los que permanecen -o se conservancontinúan explotando rápidamente.

El individuo ya no sabe vivir en pareja, se divorcia; ya no sabe comportarse en clase, molesta y habla; ya no reza en la iglesia; el año pasado, el equipo de fútbol francés no supo hacer equipo ¿acaso nuestros políticos saben construir un partido? Se habla en todos lados de la muerte de las ideologias; son más bien las identidades evocadas por ellas las que se han esfumado.

Este individuo recién nacido anuncia más bien una buena nueva. Va a nivelar las desventajas del egoísmo y los crimenes de guerra cometidos por y para la libido de identidad -de miles de muertos-, amo profundamente a estos jóvenes. Dicho esto, quedan por inventar nuevos lazos. Prueba de ello es el reclutamiento de Facebook, casi equivalente a la población del mundo.

Como un átomo sin valencia, Pulgarcita está desnuda. Nosotros los adultos no hemos inventado ningún lazo social nuevo. El dominio de la crítica y de la sospecha los deconstruye. Rarísimas en la historia, estas transformaciones que denomino hominiscentes crean, en medio de nuestro tiempo y de nuestros grupos, una fisura tan amplia que pocas miradas han logrado percibir su verdadera dimensión.

Yo la comparo, lo repito, con aquellas que intervinieron en el neolítico, al comienzo de la ciencia griega, al inicio de la era cristiana, al final de la Edad Media y en el Renacimiento.

En la saliente de esta fisura, encontramos a los jóvenes a los cuales pretendemos enseñar, en el seno de unos marcos que datan de una época que ya no reconocen: edificios, patios de recreo, salones de clase, asientos, mesas, anfiteatros, campus, bibliotecas, laboratorios, e iba a decir incluso que saberes...marcos que datan, digamos de una cierta época y adaptados a una era en donde los hombres y el mundo eran lo que ya no son.

-IV.

Tres preguntas por ejemplo: ¿Qué transmitir? ¿A quién transmitirlo? ¿Cómo transmitirlo?

\section{¿Qué transmitir? ¡El saber!}

Antes y ahora, el saber tenía como soporte el cuerpo mismo del sabio, de aedo o del griota. Una biblioteca viviente... he ahí el cuerpo enseñante del pedagogo.

Poco a poco, el saber se objetiva inicialmente en los rollos, pergaminos, soporte de la escritura, después desde el Renacimiento, en libros de papel, soportes de impresión, en fin, hoy en dia, en la red, soporte de mensajes y de información.

La evolución histórica de la pareja soportemensaje es una buena variable de la función de enseñanza. Así pues, la pedagogía cambia tres veces: con la escritura, los griegos inventan la 
paideia, una vez inventada la imprenta, los tratados de pedagogía pululan. ¿Y hoy?

Insisto. ¿Qué transmitir? ¿El saber? Lo encontrarnos en cualquier lugar de la red, disponible, objetivado ¿Transmitirlo a todos? En lo sucesivo el saber es accesible a todos ¿Cómo transmitirlo? ¡Ya está hecho!

Con el acceso a las personas vía teléfono celular, con el acceso a todos los lugares por GPS, el acceso al saber está abierto. De cierta manera, el saber siempre ha sido difundido y transmitido.

Objetivado, cierto, pero además, distribuido. No concentrado. Nosotros viviamos en un espacio métrico, referido a centros, a concentraciones. Una escuela, un campus, una clase, un anfiteatro, concentraciones de personas, de estudiantes y profesores, libros en bibliotecas, una cantidad muy grande se dice a veces, de instrumentos en los laboratorios...este saber, estas referencias, estos libros, estos diccionarios...helos aquí distribuidos por todos lados y, en especial, en su casa; mejor aún, en todos los lugares en donde se desplacen, estando alli usted puede tocar a sus colegas, a sus estudiantes por dondequiera que pase; ellos le responden fácilmente.

El antiguo espacio de las concentraciones -incluso éste en donde hablo y en donde ustedes me escuchan ¿qué hacemos aqui? - se diluye, se expande; vivimos, acabo de decirlo, en un espacio de vecindarios inmediatos, pero además, distributivo. Podría hablarles desde mi casa o desde cualquier otro lugar, y ustedes me escucharán en otra parte o en su propia casa.

No digan que el alumno carece de las funciones cognitivas que le permiten asimilar el saber así distribuido, ya que, justamente, estas funciones se transforman con el soporte. Por la escritura y la imprenta, la memoria por ejemplo, muta al punto que Montaigne prefirió una cabeza bien hecha a una cabeza bien llena. Esta cabeza mutó.

Lo mismo pues que la pedagogia fue inventada (paideia) por los Griegos, en el momento de la invención y de la propagación de la escritura; lo mismo que ella se transforma cuando emergió la imprenta, en el Renacimiento, lo mismo, la pedagogía cambia totalmente con las nuevas tecnologías.

Y lo repito, ellas sólo son una variable cualquiera entre otras tantas que he citado o que podria enumerar.

Este cambio tan decisivo de la enseñanza -cambio que repercute en el espacio entero de la sociedad mundial y el conjunto de sus instituciones caducas, cambio que no afecta de lejos, no sólo la enseñanza sino que tampoco el trabajo, la política y el conjunto de nuestras institucionessentimos una necesidad urgente de ello, pero estamos lejos de lograrlo; probablemente porque aquellos que ruedan aún en la transición entre los últimos estados no se han pensionado aún, mientras que continúan redactando las reformas, según modelos que hace tiempo caducaron.

Profesor durante cuarenta años en casi todas las latitudes, en donde esta fisura se abre a tal punto que en mi propio país, padecí estas reformas como cataplasmas en piernas de palo, como remiendos; ahora bien, las cataplasmas dañan la tibia así como los remiendos destruyen el tejido que buscan consolidar.

Si, vivimos un periodo comparable a la aurora de paideia luego que los Griegos enseñaran a escribir y demostrar; comparablemente al renacimiento que vio nacer la impresión y surgir el reinado del libro; periodo incomparable sin 
embargo, ya que al mismo tiempo que estas técnicas mutan, el cuerpo sufre también una mutación, cambian el nacimiento y la muerte, el sufrimiento y la cura, el ser en el mundo mismo, los oficios, el espacio y el hábitat.

\section{$-V$.}

\section{Envío}

Frente a estas mutaciones, conviene sin duda alguna, inventar inimaginables novedades, por fuera de los marcos caducos que forjan aún nuestras conductas y nuestros proyectos: Nuestras instituciones resplandecen con una intensidad que se parece, hoy en día, al de las constelaciones de las cuales la astrofísica nos ha enseñado antes que estaban muertas desde hacía mucho tiempo.
¿Por qué estas novedades no han aparecido? Acuso de ello a los filósofos, de los cuales hago parte, personas que tienen como oficio anticipar el saber y las prácticas futuras y que como yo, han fallado en su tarea. Comprometidos con la política día a día, no vieron venir lo contemporáneo, $\mathrm{Si}$ me hubiera correspondido esbozar la semblanza de los adultos entre los que me cuento, hubiera sido menos halagador.

Quisiera tener 18 años, la edad de Pulgarcita y Pulgarcito ya que todo está por rehacer, no, todo está por hacer.

Deseo que la vida me dé mucho tiempo para trabajar más en esto, en compañía de esos Pequeños, a los cuales dediqué mi vida porque siempre los he amado de manera respetuosa. 